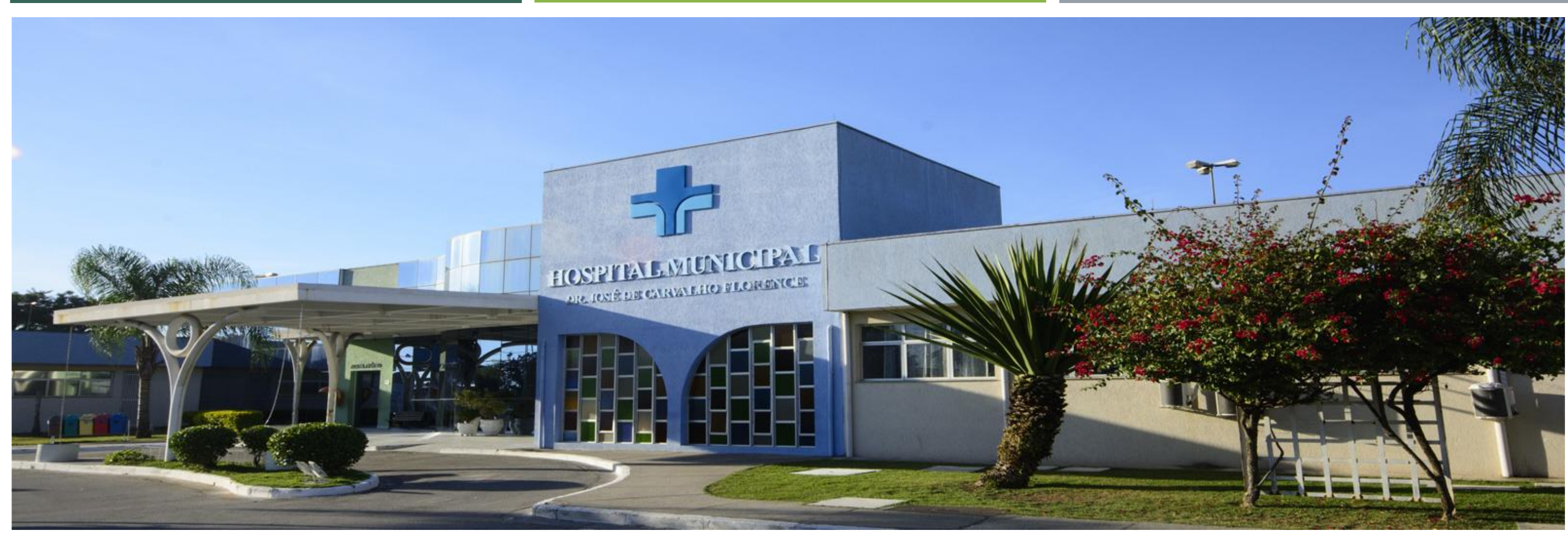

\title{
A APLICABILIDADE DA METODOLOGIA LEAN NA GESTÃO DE LEITOS DO HOSPITAL MUNICIPAL DR. JOSÉ DE CARVALHO FLORENCE (HMJCF).
}




\section{INTRODUÇÃO}

Um grande desafio da atualidade, no que se refere a saúde, é a gestão de leitos. Há décadas, a procura por um leito hospitalar vem crescendo.

O impacto de atrasos nas altas por fatores não clínicos diz muito sobre a eficiência de uma Instituição, interferindo nos custos, qualidade e adequação de cuidados. Gerenciar leitos buscando utilizar sua capacidade máxima, com segurança, é um desafio do HMJCF, que no último ano implantou a metodologia Lean para tratar o

assunto.

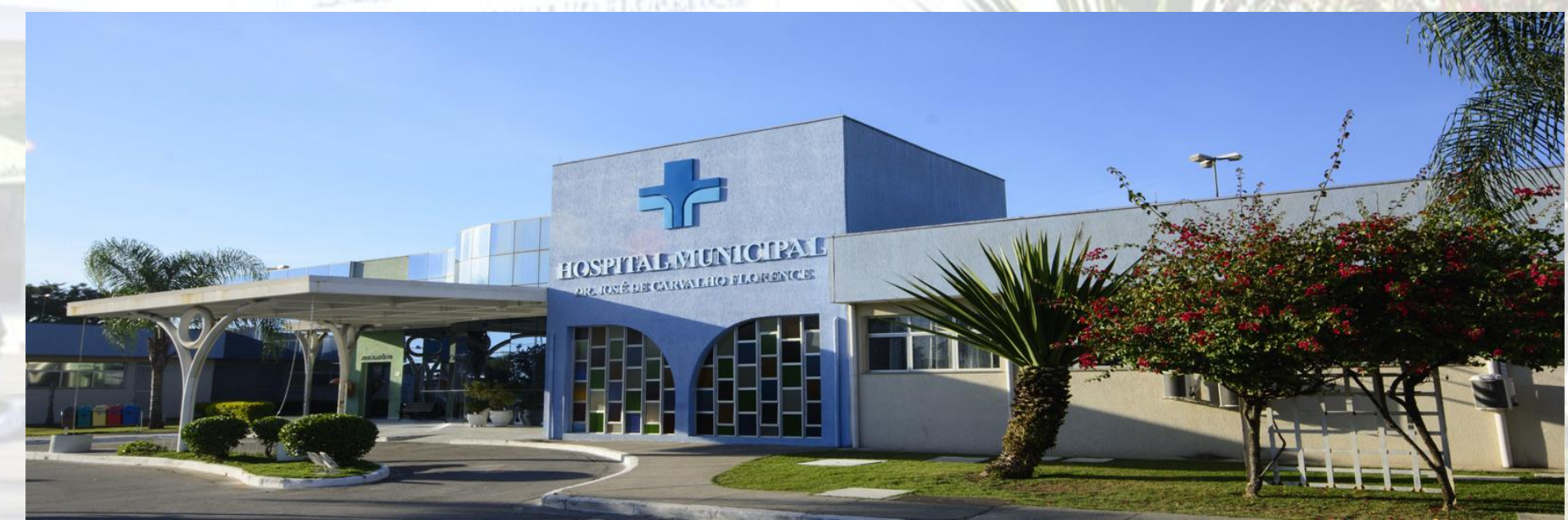




\section{OBJETIVO}

Diminuir a taxa de permanência da unidade de clínica médica e aumentar a adesão da alta antes das II hs.

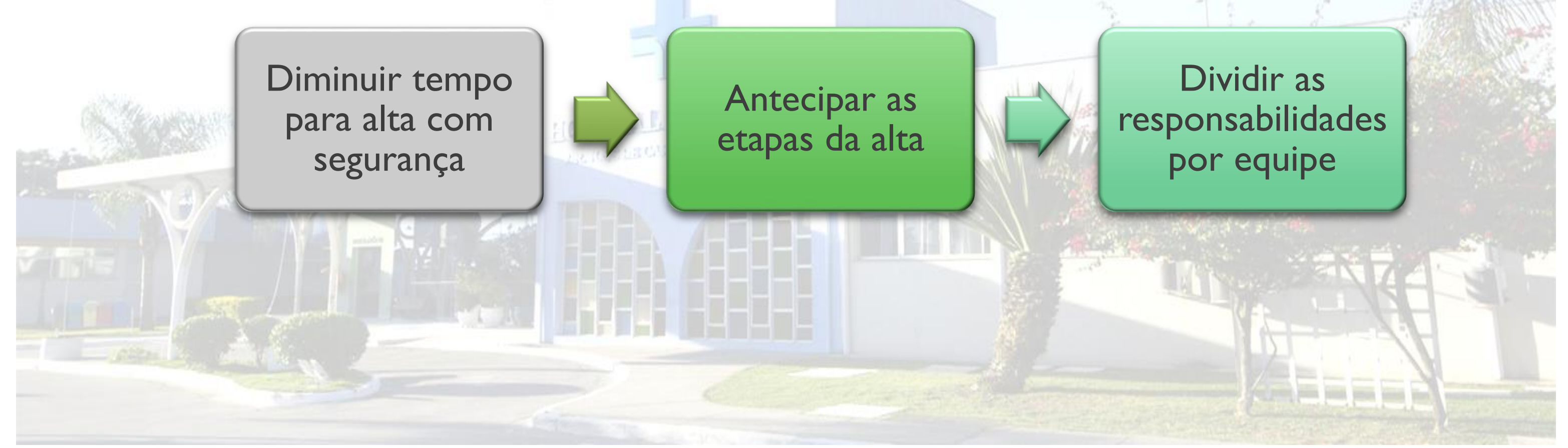




\section{METODOLOGIA}
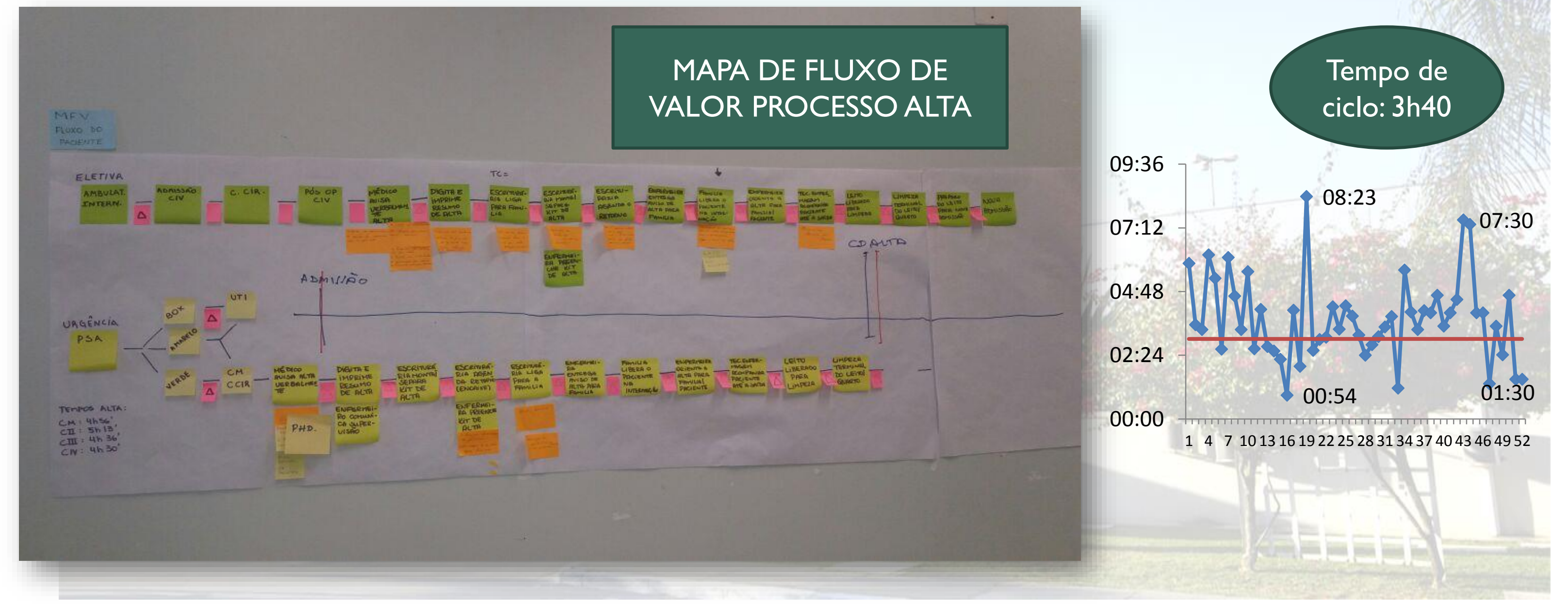


\section{METODOLOGIA}

\section{Foi realizado um A3 (método Lean) para investigar os problemas.}

\section{As altas saem em sua maioria após ás $15 \mathrm{hs.}$}

- Residente normalmente deixa o resumo de alta feito no dia anterior (3 min) mas preceptor tem que validar a alta.

- As visitas médicas não se iniciam pelos pacientes de alta;

- Visitas médicas demoradas - Hospital de ensino;

- Escriturária liga para a família só após alta efetuada $(5 \mathrm{~min})$

- Escriturária realiza encaixe no ambulatório de pós alta no dia da alta (10 min) formaliza alta no setor de internação (máx. $15 \mathrm{~min}$ )

- Orientação do enfermeiro demora até 5 minutos.

- Família demora para chegar quando não tem previsão da alta.

- Limpeza do leito (máx. 30 min)

- Existem pré-conceitos formados: Falta de documentos (3 no mês),

- a família não quer vir buscar (1 no mês), o paciente não quer ir embora...

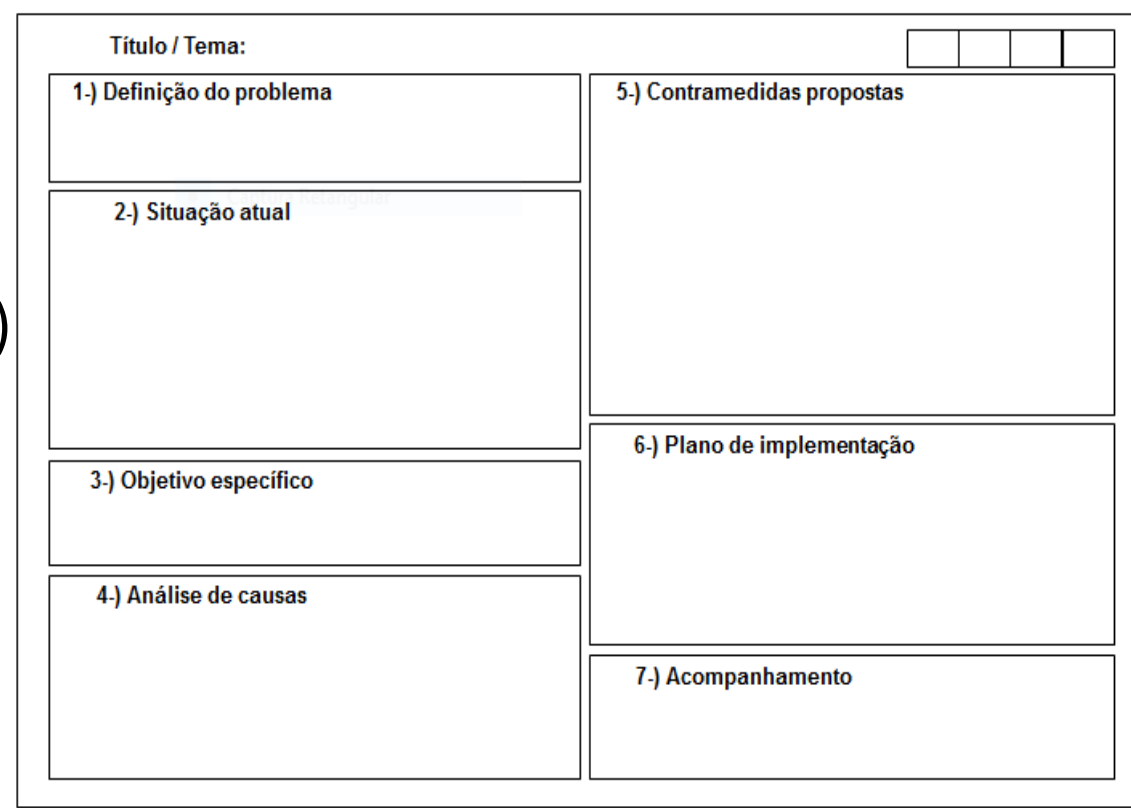




\section{METODOLOGIA: TRABALHO PADRONIZADO}

\section{ROUND}

Quantos pacientes com possível alta amanhã?

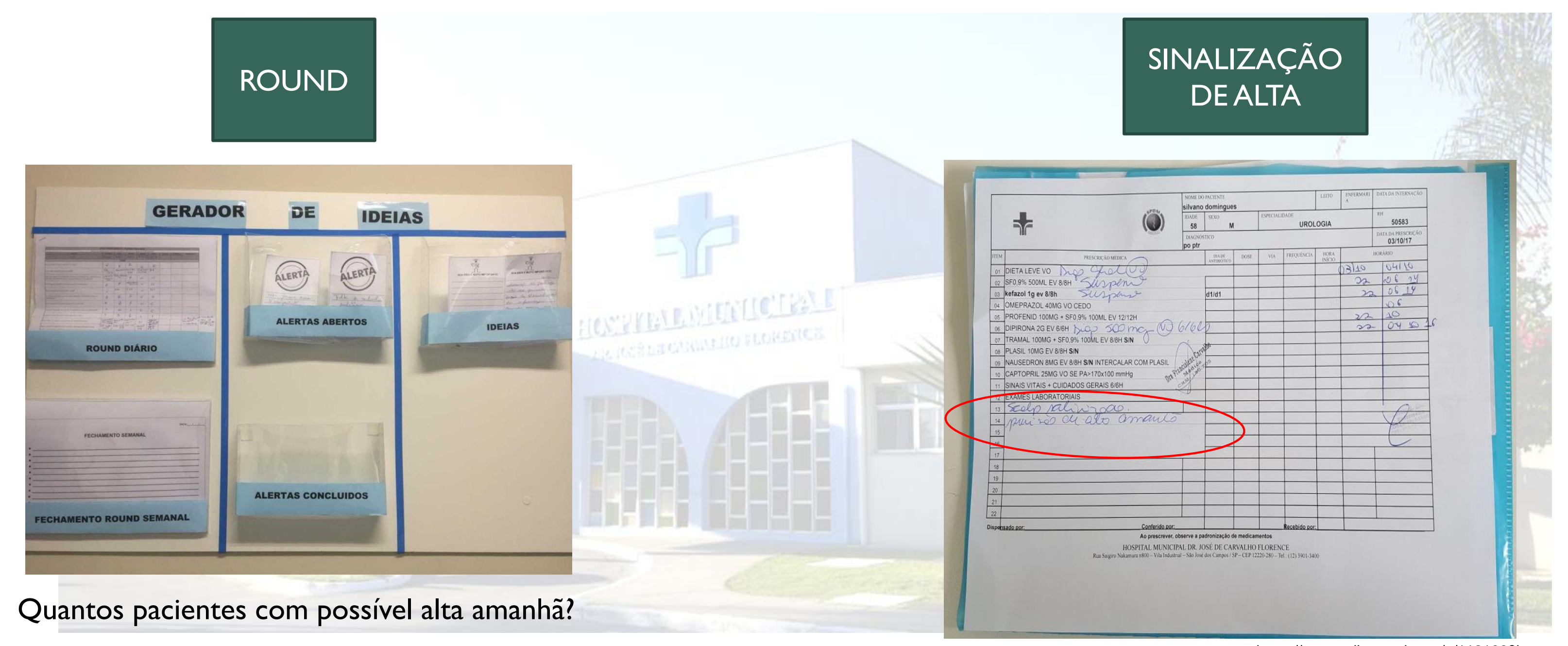

SINALIZAÇÃO DE ALTA 


\section{INTRODUÇÃO}

Propor

forma de

deixar visível

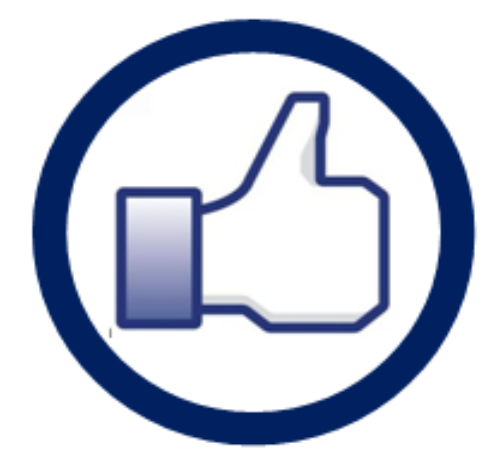

\begin{tabular}{|c|c|c|c|c|}
\hline 4001] grof & & Succas Mendes Maralläes & Temanali & \\
\hline 402 aed & 66199 & Dimas AugusTo Dugue costa & 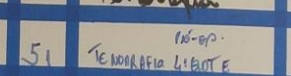 & \\
\hline 403 of & $260^{4}$ & RAIMUNDO de ARAúJo LOPES & 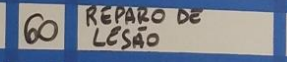 & Ag Aral cxapd \\
\hline 404 G $0^{2}$ & ser & Lazano neraes & Giop. vasal & \\
\hline 4056 & 2619 点被 & LEONINA CaNGiDO OA COSTA & 80 Histerectomia, & \\
\hline $40680^{100}$ & $28 / 9$ ther & Aline Flountino & Rea. Fratis onos & \\
\hline 40701006 & | $419 \mid$ & Joár des Sontes & 76 DACP & 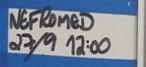 \\
\hline 408 shof & 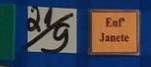 & Redrigo Cezar da Silva & 36 Rinoam brectomant I & Eivanas \\
\hline 409 & 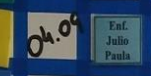 & Jox' Arimatera & 68 Hidrocentaliat DUP & Aganal CM \\
\hline 410 of & 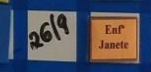 & DIOGILVAN NOLASCO DA SILVA & 54 TENORrafia calca : & \\
\hline 411 bes & 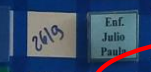 & IUARCO AURELIO NESOVYA & 35 Jusiso himice & \\
\hline 412 glop & 249 teris & Geraldo Placido (a) & Temonalia & \\
\hline 413 CG & 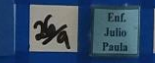 & MARIA SILUANIA OA SILWA & 33 COLECistectomia & \\
\hline 414 GO & sine & Maria Apancida Sclveira (3) & Hisreecc. SOB & \\
\hline 415 CG & & GRAZIELE DOS SANTOS & 17 Exeesscisto & \\
\hline 416 ped & 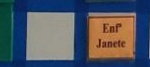 & Nayara Mary do Amaral & exeresse e Sinvefa & \\
\hline 417 & 20619 int & Jonatas varela arruda & 27 Colono & \\
\hline 418 है & $\Leftrightarrow$ & ANTONIO ANESTACIO & $66 \sqrt{15}$ & \\
\hline
\end{tabular}




\section{METODOLOGIA}
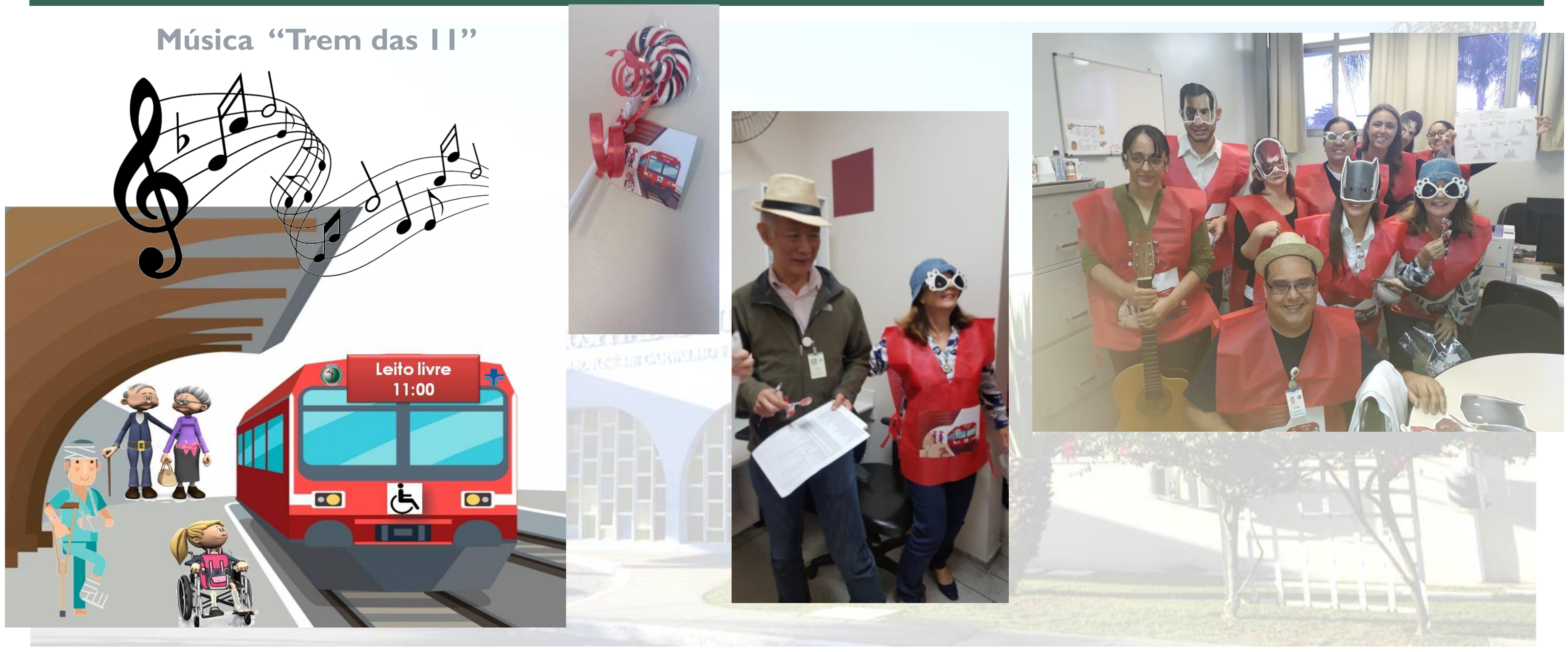


\section{RESULTADOS}

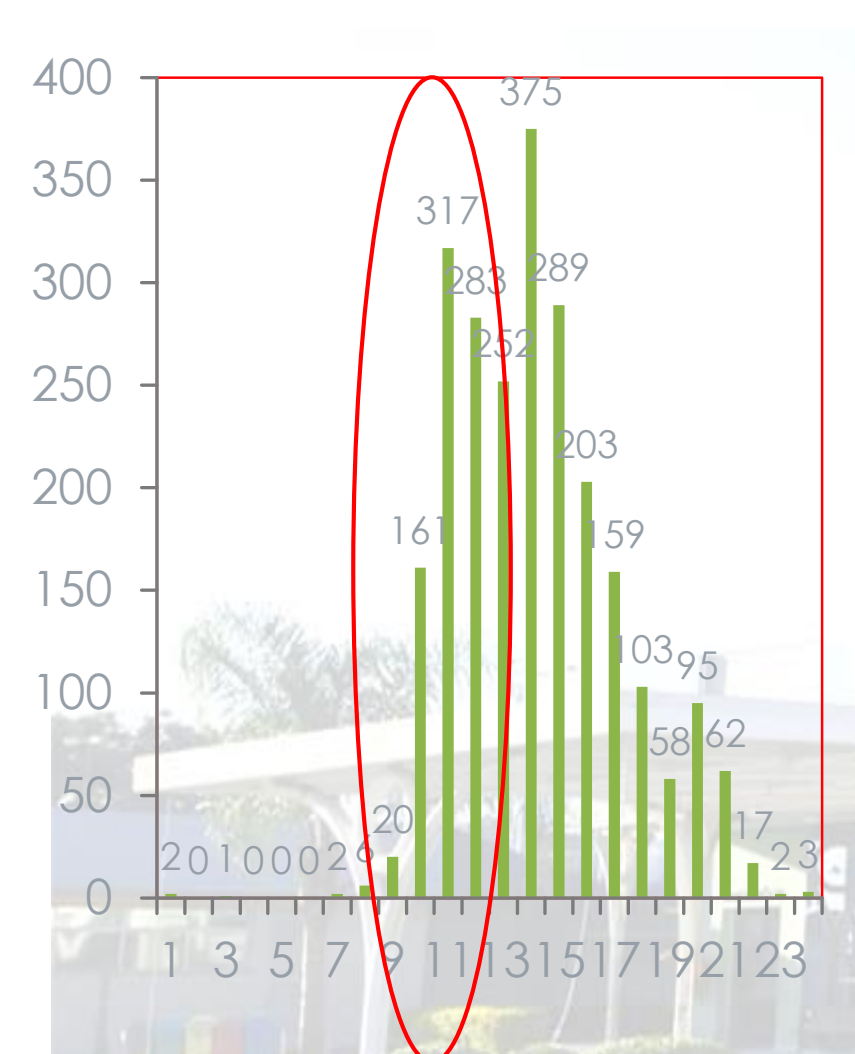

Altas Hospitalares antes das $11 \mathrm{~h}: 8 \%$

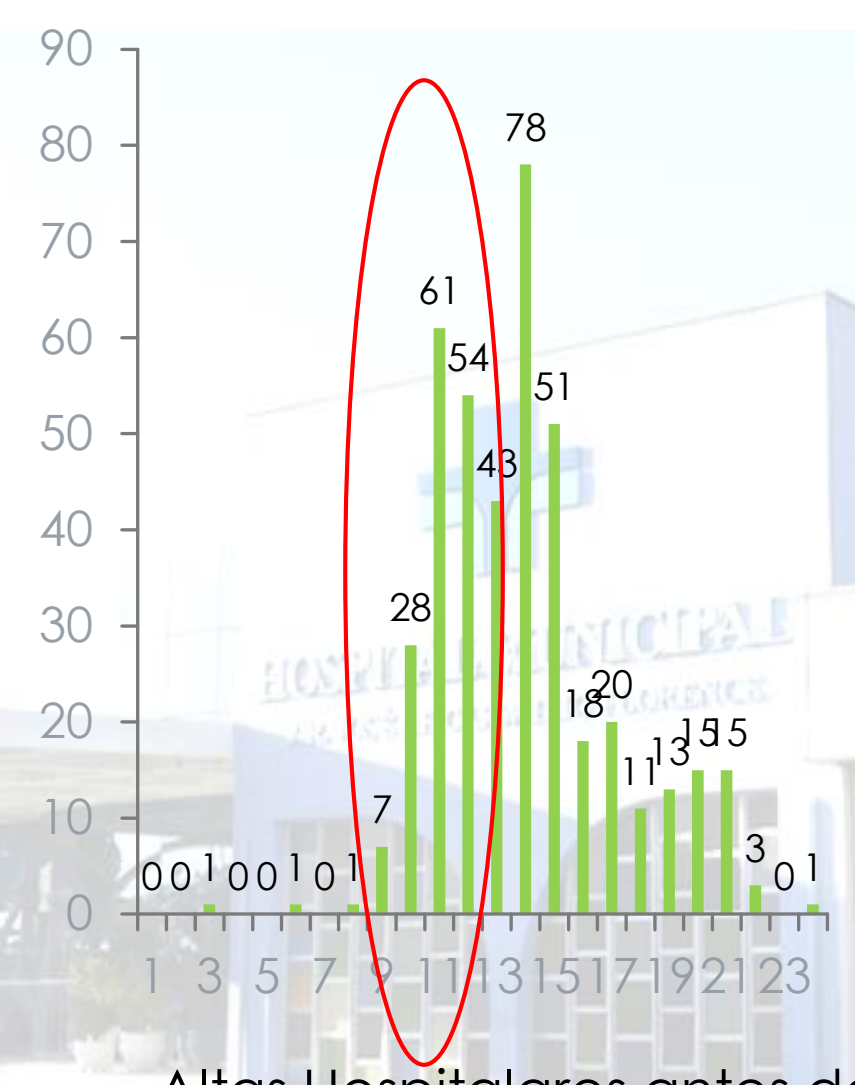

Altas Hospitalares antes das 11h: $23 \%$

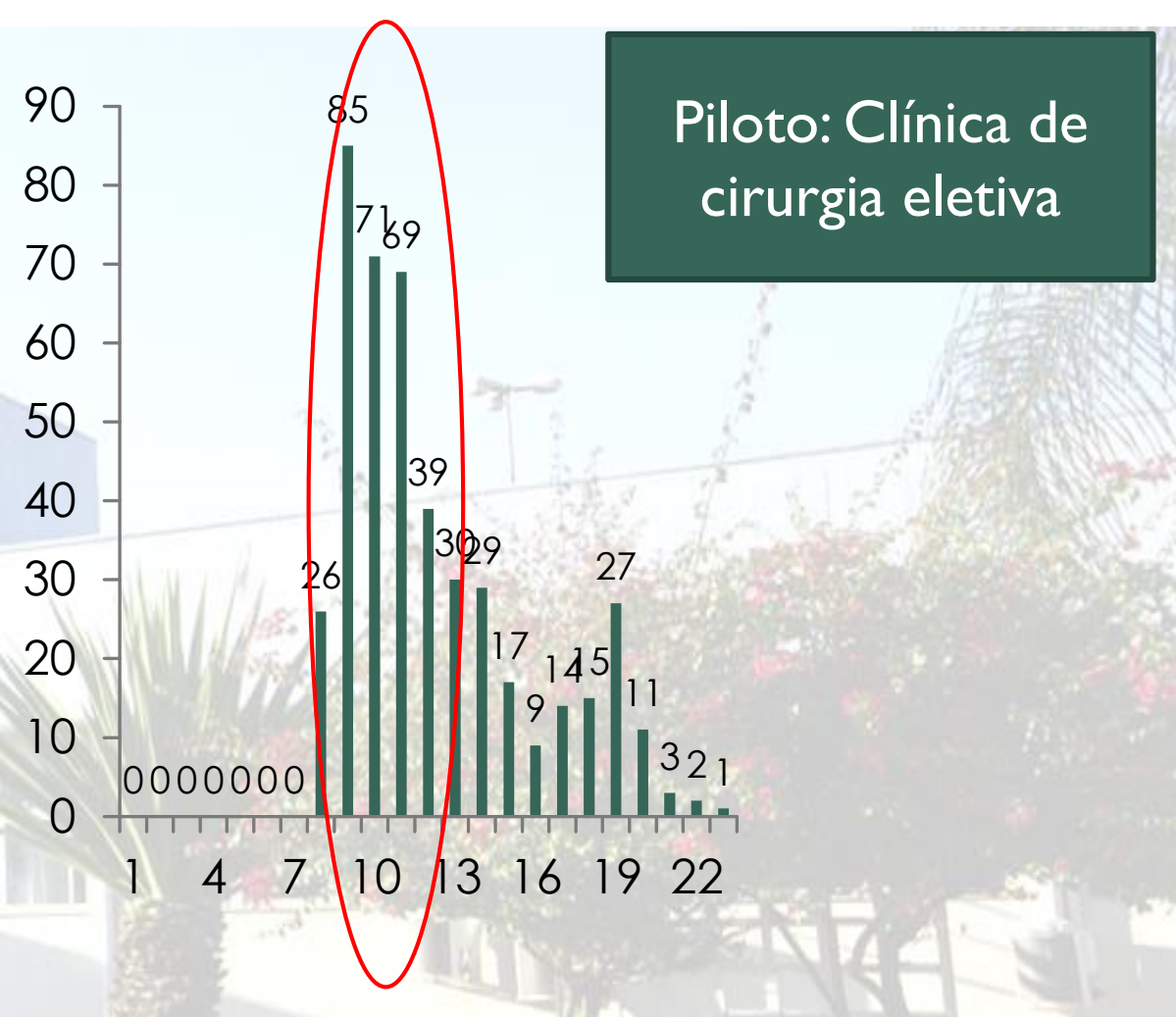

Altas Hospitalares antes das 11h: $41 \%$ 


\section{RESULTADO}

\section{Clínica médica}

Meta $30 \%$ em 6 meses

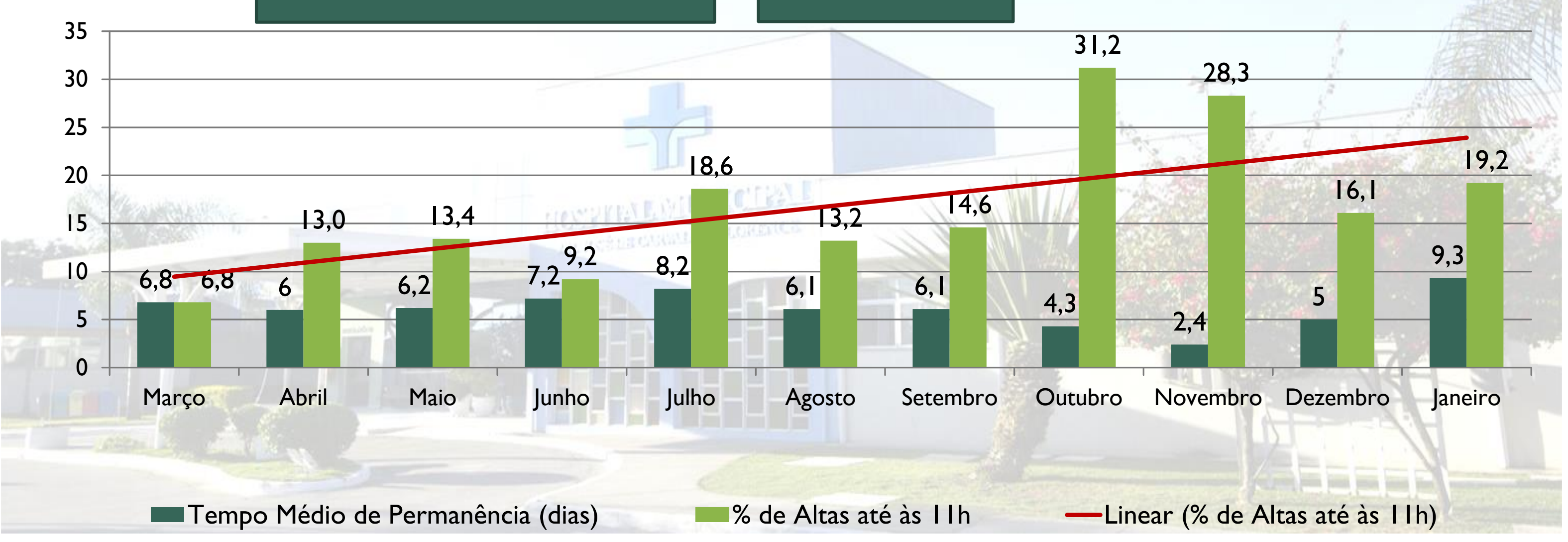




\section{RESULTADO}

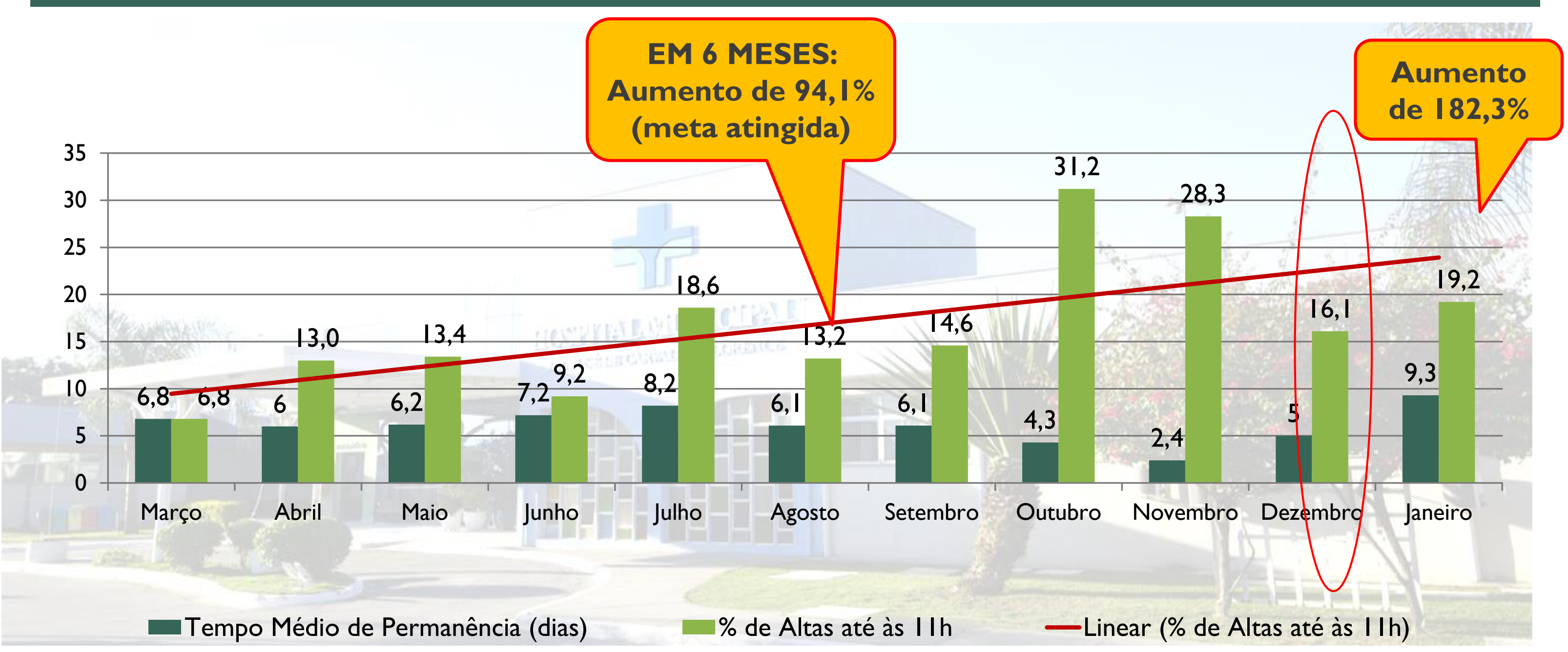




\section{CONCLUSÃO}

Adequar a comunicação e determinar um trabalho padronizado para antecipar as etapas de alta foram extremamente relevantes para os resultados.

A campanha leito livre proporcionou a gestão visual para que a equipe multidisciplinar acompanhasse o resultado do processo.

O envolvimento de todos os membros da equipe foi determinante no sucesso do projeto.

A metodologia Lean mostrou-se eficaz para a redução do desperdício e gerenciamento diário dos leitos.

A meta foi alcançada.

Ainda há variabilidade no processo. 


\section{OBRIGADA!}

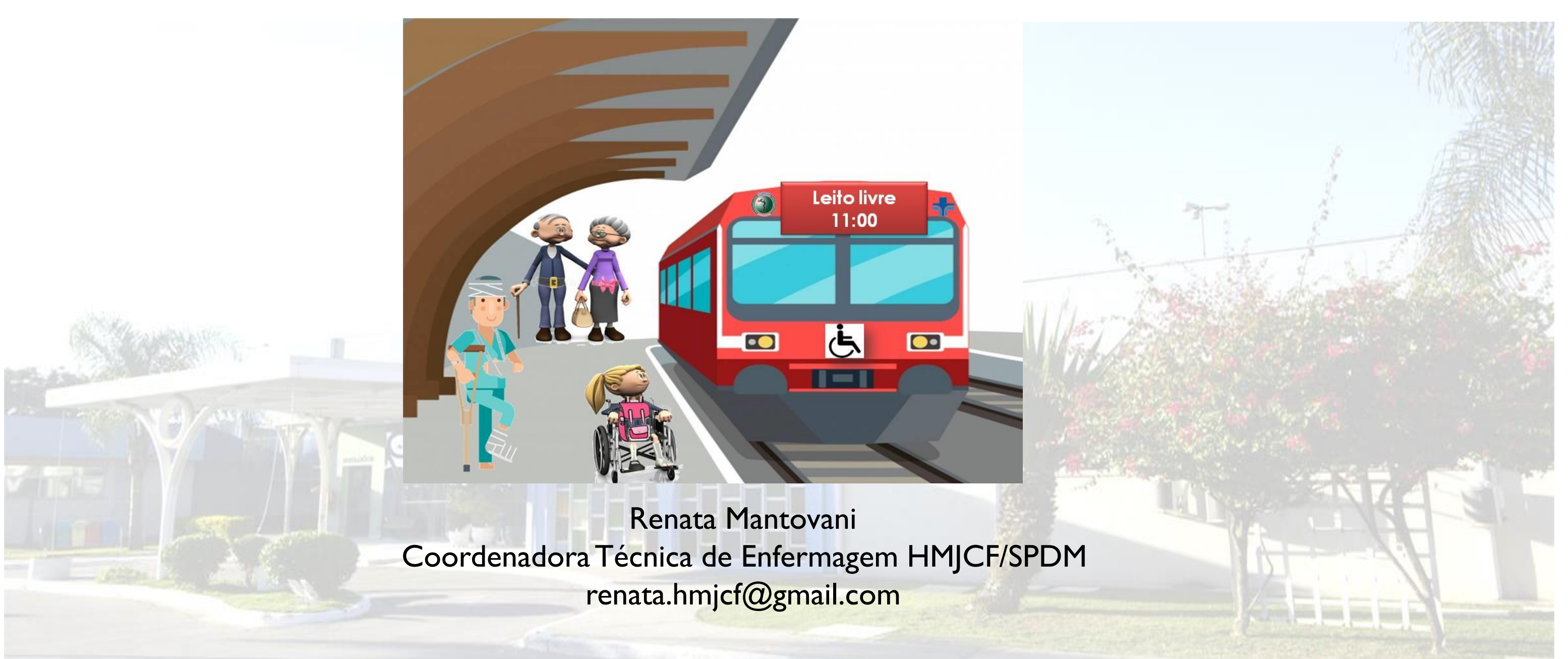

